\title{
FORMAÇÃO DO PROFESSOR DE FILOSOFIA E DE SOCIOLOGIA PARA O ENSINO MÉDIO: contribuição do Programa de Residência Pedagógica
}

Celso EIDT ${ }^{1}$

Gustavo Giora ${ }^{2}$

O programa da Residência Pedagógica constitui um desafio acadêmico novo no interior do processo de formação de professores. Não apenas por ser o programa lançado em sua primeira edição e com alguns percalços, mas, acima de tudo, pela natureza e complexidade de sua concepção. Por propor ações que abrangem e contemplam instituições educacionais de distintos sistemas de ensino, a organização e o desenvolvimento dos Projetos nele contemplados têm exigido e continuam demandando um trabalho conjunto e articulado entre as instituições educacionais, os núcleos escolares e os sujeitos diretamente envolvidos. Essa é uma perspectiva de contribuição positiva e promissora do Programa no que diz respeito à formação do futuro profissional em educação, já que pretende integrar

\footnotetext{
1 Doutor em Filosofia, professor-adjunto da UFFS, coordenador do núcleo do Programa de Residência Pedagógica Multidisciplinar (Filosofia e Sociologia) campus Erechim. Contato: celso.eidt@uffs.edu.br.

${ }^{2}$ Doutor em Ciência Política, professor-adjunto da UFFS, colaborador do núcleo do Programa de Residência Pedagógica Multidisciplinar (Filosofia e Sociologia) campus Erechim. Contato: gustavo.giora@uffs.edu.br.
} 
os acadêmicos dos cursos de licenciatura da universidade com as instituições da educação básica, oportunizando desafios e experiências práticas nas escolas, tarefa antes delegada às disciplinas de estágio ou a ações pontuais.

É em relação à dinâmica do processo de formação do futuro professor para o exercício profissional na educação básica que o Subprojeto da Residência Pedagógica na área de Filosofia e Sociologia encontra os maiores desafios e potenciais. $\mathrm{O}$ tema da formação do professor de filosofia e de sociologia para a educação básica foi um dos pontos que, nas décadas de 1990 e 2000, foi pauta de encontros e eventos ligados ao retorno obrigatório dessas disciplinas ao Ensino Médio e oportunizou algumas transformações significativas no interior da revisão dos Projetos Políticos Pedagógicos dos Cursos de Licenciatura na área.

Não é desconhecida a justa crítica à tradicional dicotomia nos Cursos de Licenciatura entre a formação acadêmica stricto sensu e a formação pedagógica lato sensu. Ou seja, historicamente, a formação filosófica e sociológica era tributada ao núcleo duro do rol de disciplinas das grades curriculares desses Cursos, ao passo que a formação pedagógica e o tratamento dos assuntos do ensino eram de responsabilidade dos professores da área da educação. Dicotomia essa que equacionava a formação pedagógica por uma didática geral e externa à formação específica de cada área do saber. Ou seja, a formação para o ensino era algo externo, quase que anexo, à formação propriamente filosófica ou sociológica.

O debate acerca da formação filosófica e sociológica para o ensino, a especificidade da formação de professores nessas áreas, avançou muito, operou mudanças nos Cursos de Licenciatura na área e equacionou vários problemas, mas ainda constitui um desafio para todos aqueles que se ocupam com a educação básica. Construir, a partir do Programa da Residência Pedagógica, um Projeto comum 
na área de Filosofia e Sociologia, reforça o compromisso dos Cursos de Licenciatura da UFFS com as condições e possibilidades do ensino e constitui mais um passo importante para qualificar a formação do professor e, assim, preparar profissionais qualificados para atuar na educação básica.

Um dos avanços significativos operados pelos Cursos de Graduação em Filosofia e Sociologia da UFFS foi a redefinição da relação entre a formação teórica básica na área teórica específica e a formação didático-pedagógica, articulando a integração curricular entre o núcleo teórico duro e o fazer pedagógico que lhe é próprio. As exigências da formação do professor se tornaram exigências filosóficas e sociológicas. Nessa perspectiva, a área da formação pedagógica deixou de ser pensada como apêndice, algo externo ou anexo à formação específica para se converter em dimensão essencial da formação do graduando nessas áreas. A integração orgânica dos componentes didático-pedagógicos e aqueles da formação básica, na integralização curricular das áreas, vão dando um novo perfil aos futuros professores. Embora seus resultados ainda sejam incipientes no interior das instituições escolares, dados os limites do contexto educacional brasileiro e das circunstâncias adversas e, historicamente avessas à presença dessas áreas do conhecimento nos currículos escolares, não se pode desconhecer a relevância desse passo na qualificação da formação do professor.

No interior desse cenário acadêmico positivo para consolidar a formação dos professores de Filosofia e de Sociologia, o Programa da Residência Pedagógica, devido à sua natureza e concepção, agrega novo potencial, focado na valorização da dimensão prática, da inserção ativa e organizada dos acadêmicos no espaço da educação básica. Ou seja, a formação do professor da educação básica como propósito maior do Programa da Residência Pedagógica vai ao encontro da política de formação de professores da UFFS e também está próximo 
de várias iniciativas ainda recentes no marco da legislação brasileira e das políticas de governo voltadas ao sistema da educação básica.

O programa da Residência Pedagógica apresenta entre suas diretrizes aquela voltada a:

Aperfeiçoar a formação dos discentes de cursos de licenciatura, por meio do desenvolvimento de projetos que fortaleçam o campo da prática e conduzam o licenciando a exercitar de forma ativa a relação entre teoria e prática profissional docente, utilizando coleta de dados e diagnóstico sobre o ensino e a aprendizagem escolar, entre outras didáticas e metodologias. (BRASIL, 2018)

O Subprojeto do Programa da Residência Pedagógica em vigor nos Cursos de Filosofia e Sociologia tem como objetivo geral propiciar espaços de aprendizagem docente aos acadêmicos participantes. Aprendizagem docente que vai ao encontro da Política Institucional da UFFS para Formação Inicial e Continuada de Professores da Educação Básica. Política traduzida em princípios que orientam as licenciaturas para conceber a "docência como atividade profissional intencional e metódica" e promover a "a articulação com a educação básica pública e outros espaços educativos escolares e não escolares". Aos estudantes é dada a oportunidade de vivenciar e de pensar a docência não apenas como atividade profissional, mas como formação acadêmica, como apropriação da experiência no interior das instituições educacionais, como projeto de construção de perspectivas e alternativas para o ensino na área das ciências humanas.

A formação para o ensino, um desafio ainda recente, tem um significado particularmente relevante nos Cursos de Filosofia e Sociologia, dada a peculiar situação do seu ensino na educação básica. Como já referido, é bastante recente o movimento político-pedagógico focado no retorno das disciplinas de filosofia e sociologia ao currículo do Ensino Médio. Fato que merece registro pelo caráter dessa decisão e pelas implicações de sua consolidação. 
Não é fato desconhecido que as áreas de Filosofia e de Sociologia têm uma trajetória de descontinuidades no interior dos currículos escolares dos níveis de formação escolar que antecedem a academia. Descontinuidade diretamente relacionada aos fatos e às determinações políticas brasileiras e sua força e disposição para tratar a educação como política de governo. Um exemplo marcante, devido ao lastro de suas consequências negativas, é o fato de a Filosofia e a Sociologia terem sido banidas das grades curriculares com a Reforma do Ensino Médio, doravante focando na Formação Profissional (Lei n. 5.692, de 11 de agosto de 1971). O fato é que um regime de poder autoritário e fechado impôs um modelo de educação restritivo, unilateral e avesso às humanidades. Com a abertura política, a partir dos anos de 1980, uma nova proposta de educação, laica, democrática e republicana ganhou força e no seu interior se confere cidadania escolar ao saber filosófico e sociológico, cujo retorno obrigatório ao ensino médio gerou um lastro de expectativas e dúvidas.

O propósito aqui não é o de examinar controvérsias acerca do sinuoso caminho pelo qual se deu o retorno dessas áreas ou disciplinas ao ensino escolar, mas sim refletir sobre as contribuições que o Programa da Residência Pedagógica pode dar para qualificar o seu lugar na escola.

É preciso considerar, no entanto, no contexto da educação escolar brasileira, a fragilidade que gera a dependência de políticas governamentais, a ausência de políticas de Estado, o caráter negativo que em certos contextos históricos se imprime à formação de professores nas áreas das Ciências Humanas e da presença dessa área na educação básica. Visões autoritárias, pragmáticas, tecnicistas ou imediatistas costumam dispensar as contribuições das Humanidades no processo de formação das crianças e jovens. Em outros contextos históricos, o processo pode ser revertido pela abertura de espaços e pela promoção de relações democráticas no processo de ensino-aprendizagem. 
O contexto político constitui um marco forte na concepção e na determinação do lugar da área de Filosofia e Sociologia no ensino básico. Vejamos aspectos dessa problemática: não foi de pouco significado o movimento de mobilização e discussão acerca da relevância e da pertinência de uma proposta de educação escolar que contemple a formação integral das crianças e de jovens, promovendo, assim, uma revisão curricular que contemplasse áreas antes dela excluídas, como é o caso da filosofia e da sociologia.

$\mathrm{Na}$ esfera da legislação federal não é desconhecido o papel que os diversos movimentos e organizações da comunidade filosófica e sociológica assim como distintas frentes de educadores e estudantes exerceram para o retorno da filosofia e da sociologia ao currículo das escolas. Movimento político educacional que deu suporte e legitimidade às decisões que surgiram no marco da legislação para avançar na reformulação da educação básica e na democratização dos saberes.

Um marco importante no tratamento das questões relativas à formação de professores foi a criação de documentos oficiais, como a Lei de Diretrizes e Bases da Educação (1996), os Parâmetros Curriculares Nacionais para o Ensino Médio (MEC 1998) e a Lei CNE/ CP n. 2/2002, que estabelece 400 horas de prática como componente curricular e 400 horas de estágio curricular obrigatório. Outro momento importante para o ensino de filosofia e sociologia foi o surgimento dos debates promovidos pela Diretoria de Ensino Médio do MEC nos anos de 2004 e 2005, em torno dos Parâmetros Curriculares Nacionais para essas disciplinas no Ensino Médio (PCNEM), assim como a elaboração das Orientações Curriculares do Ensino Médio (OCEM). Também cabe registrar a relevância dos debates promovidos em eventos voltados ao retorno da filosofia e da sociologia como disciplinas obrigatórias no ensino médio.

Em 7 de julho de 2006, o Conselho Nacional de educação (CNE) aprovou um parecer exigindo a presença da filosofia e da sociologia 
como disciplinas obrigatórias no currículo do Ensino Médio das escolas públicas e privadas do Brasil (assegurada pela Lei n 11.683, de 2 de junho de 2008). Também as orientações estabelecidas pelas Diretrizes Curriculares para os Cursos de Graduação em Filosofia contribuem para pensar a especificidade da formação dos professores de filosofia. As Diretrizes sustentam a tese de que

O licenciado deverá estar habilitado para enfrentar com sucesso os desafios e as dificuldades inerentes à tarefa de despertar os jovens para a reflexão filosófica, bem como transmitir aos alunos o legado da tradição e o gosto pelo pensamento inovador, crítico e independente. (BRASIL, 2001, p. 39)

A perspectiva positiva em relação à formação do professor de Filosofia e Sociologia veio acompanhada, depois de suas inclusões como disciplinas obrigatórias, de um conjunto de expectativas, preocupações e necessidades por parte das escolas acerca das condições de seu ensino. O que singulariza o ensino nessas áreas no interior de uma instituição escolar laica, democrática, fundada na ideia republicana de educação? O que são e quais são as competências e habilidades próprias para o exercício do ensino de Filosofia e Sociologia? Que habilidades e competências especificamente filosóficas e sociológicas são necessárias e podem contribuir para a formação dos estudantes?

Vale ressaltar que, conforme as Orientações Curriculares para o Ensino Médio, esse ensino não mais é concebido como fase preparatória para o vestibular ou para o mercado do trabalho, mas como fase conclusiva do ensino fundamental, que tem como objetivo central a formação integral dos estudantes, e que tem uma proposta político-pedagógica menos focada no acúmulo de conhecimentos do que no domínio dos recursos necessários ao aprender e a continuar aprendendo. Trata-se de uma educação centrada no ser humano, que 
não busca a mera preparação técnica, mas sim o desenvolvimento pleno do estudante como pessoa, sua formação ética, a promoção da autonomia intelectual e do pensamento crítico, sua preparação para o trabalho e o desenvolvimento de competências para continuar aprendendo.

Um diagnóstico bastante comum alerta sobre as resistências que as disciplinas de filosofia e sociologia, ou das Humanidades de forma geral, enfrentam no espaço escolar. Dificuldades oriundas não apenas do momento histórico de sua consolidação, mas também da falta de professores com formação específica, carência de materiais bibliográficos e didáticos adequados, de problemas metodológicos, de referências em experiências de ensino, assim como das condições e da especificidade dos saberes na área das humanidades e a postura diante dela. Ou seja, na escola da educação básica, o ensino de Filosofia e Sociologia é precário. O seu lugar ainda é periférico. Parece cumprir mais uma exigência burocrática do que compor um ideal de formação. Ainda não foi construído um lugar apropriado, com profissionais qualificados que possam ministrar um programa de ensino elaborado a partir do que é próprio das referidas áreas. Essa é uma exigência para possibilitar um ensino significativo que contribua para a formação dos jovens da educação básica.

As atividades do Subprojeto da Residência Pedagógica na área de Filosofia e Sociologia tem relevância para reforçar ações no contexto escolar, mapear potenciais e dificuldades e pensar perspectivas novas para suprir as demandas. A inserção, a partir e durante a formação acadêmica, no contexto escolar, e a imersão na vida cotidiana da escola permitem aos estudantes que participam do Programa conhecer a realidade, incorporar a formação acadêmica à experiência prática na escola, formar uma consciência clara dos desafios, das potencialidades e das necessidades da educação básica.

Na tarefa da inserção dos Residentes na escola da educação básica, é notório o desafio de promover um trabalho conjunto entre 
os acadêmicos dos Cursos de Filosofia e Sociologia e isso não diz respeito apenas aos acadêmicos ou ao exercício profissional na educação básica, mas aponta para a necessidade de promover debates e de buscar uma maior articulação dos cursos de formação no interior das instituições acadêmicas. Na academia, a formação do professor continua focada na tradicional organização curricular disciplinar estanque, dos Cursos centrados em seu próprio campo teórico, pensados na perspectiva da divisão dos saberes e voltados ao exercício disciplinar específico no interior da educação básica.

O trabalho conjunto dos Residentes nas três escolas da Educação Básica em que o Subprojeto da área de Filosofia e Sociologia aponta a problemática de um projeto de formação do professor em dissonância com as exigências e as condições de trabalho. Os profissionais da educação atuam não apenas na área específica em que realizaram seus Cursos de Licenciatura, mas assumem atividades segundo as exigências e as necessidades da escola, ou seja, lecionam diferentes disciplinas, por exemplo, Filosofia, Sociologia, Religião e mesmo História, o que imediatamente aponta para a dissonância entre a formação acadêmica e o real contexto escolar. Não se consolida uma área do saber sem apresentá-la em sua especificidade e de maneira qualificada para que possa estimular os estudantes, despertar seus interesses pelas questões e pelos debates que a área propõe e, assim, contribuir para promover uma formação significativa e plena das capacidades e dos potenciais dos jovens. Embora o Projeto da Residência em questão esteja contemplado qualificadamente com Professores Preceptores com formação filosófica e longa experiência no ensino - nas escolas, não há professores formados em Sociologia (ou mesmo Ciências Sociais) - essa não é uma regra das escolas que pertencem ao sistema da Rede Estadual de Ensino. Inclusive cabe lembrar que os últimos concursos públicos já não fizeram a seleção dos professores por Cursos, mas, por áreas. Esse é um cenário real que se impõe no cotidiano escolar e na vida profissional dos professores. 
Em relação aos aspectos positivos que o Programa da Residência Pedagógica possibilita, destacamos a opção pelos estudantes já na segunda metade dos seus respectivos Cursos de Licenciatura. Esses estudantes já têm boa formação acadêmica, resolveram eventuais dúvidas acerca da pertinência de suas opções e estão decididos a obter sua conclusão. Muitos têm a meta clara de atuar como professores na educação básica e manifestam preocupações no que se refere aos desafios que a escola e os educadores enfrentam no cotidiano da vida escolar. Ou seja, o foco no ensino os acompanha durante a formação e encontra resposta positiva nas atividades da Residência Pedagógica. É marcante a forma com a qual os Núcleos dos Residentes apostam na valorização do trabalho coletivo e interdisciplinar que está sendo desenvolvido tanto no interior do grupo, por seus membros participantes, quanto pela interação deste no interior das instituições escolares.

O compromisso dos acadêmicos com o Programa é reforçado pelas exigências desse programa no sentido da realização integral do Plano de Atividades e do cumprimento do montante das horas contratadas. Há pouca desistência por parte dos estudantes, o que dá maior estabilidade e continuidade às ações e às intervenções nas escolas.

O aproveitamento por parte dos Cursos de Licenciatura da UFFS do tempo e das atividades dos Residentes nos CCRs de Estágio igualmente merece registro. Não se trata de simples troca de funções, mas do reconhecimento da relevância e da pertinência das atividades realizadas durante a participação na Residência Pedagógica. A imersão na escola com o acompanhamento de um Preceptor, assim como a orientação por parte da equipe de Coordenação do Subprojeto na UFFS, dá suporte teórico e legitimidade às atividades.

A reflexão sobre o ensino de Filosofia e de Sociologia aponta grandes desafios e, igualmente, enormes potencialidades no processo de formação dos jovens da educação básica. Ampliar e aprofundar 
as atividades voltadas ao ensino e à formação do professor contribui para a promoção e a qualificação profissional, consolida a política de formação acadêmica articulada com o sistema educacional como um todo.

Ao concluir, podemos afirmar que o Programa da Residência Pedagógica vem contribuindo para promover a qualificação do professor de Filosofia e de Sociologia por meio do intercâmbio teórico e do exercício da mediação pedagógica na vivência prática do processo de ensino aprendizagem nas escolas da educação básica.

Reconhecer e apontar as perspectivas positivas, os potenciais e as contribuições que as ações lançadas pelo Programa da Residência Pedagógica, uma ação pontual das políticas de governo, possibilitam, em relação ao processo de formação do professor e da qualificação do ensino na educação básica, e exigem, ao mesmo tempo, atenção e alerta para a inversão da relação entre políticas de governo e políticas de estado para a educação e suas implicações na consolidação de uma educação laica, democrática e autônoma. Cabe destacar as manifestações e as iniciativas recentes do atual governo em relação às políticas educacional, já que mais uma vez se lançam dúvidas sobre o lugar e a legitimidade da formação de professores na área de Filosofia e Sociologia, assim como o ensino nessas áreas na educação básica. É a face sombria das políticas do atual governo. O olhar avesso e adverso sobre os saberes filosóficos e sociológicos na educação brasileira, a desconfiança e o arbítrio em relação à presença da Filosofia e da Sociologia no Ensino médio têm sombreado os esforços e os alcances na inserção e na consolidação de um ensino significativo nessas disciplinas na etapa final da formação na educação básica. Novamente, os rumos da educação escolar brasileira estão entregues às políticas governamentais, suas descontinuidades e determinações ideológicas. Decisões arbitrárias e informações desencontradas de governos estão em choque com as necessidades e os interesses da 
comunidade de educadores e das instituições escolares que precisam de políticas de Estado que possibilitem a organização e a consolidação da educação em princípios laicos, democráticos e científicos.

\section{Referências}

ADORNO, Theodor W. Educação e Emancipação. 2. ed. São Paulo: Paz e Terra, 2000.

ARANHA, Maria Arruda; MARTINS, Maria Helena Pires. Filosofando: uma introdução à filosofia. São Paulo: Moderna, 1996.

ARANHA, Maria Arruda; MARTINS, Maria Helena Pires. Temas de Filosofia. São Paulo: Moderna, 1995.

ARANTES, Paulo et al. A filosofia e seu ensino. São Paulo; Petrópolis; Educ; Vozes, 1995.

BRASIL. Lei 5.692, de 11 de agosto de 1971. Brasília, Senado Federal, 1971.

BRASIL. Diretrizes Curriculares Nacionais dos Cursos de Filosofia. Parecer CNE/CES 429/2001. Brasília: Ministério da Educação, $04 / 07 / 2001$.

BRASIL. Capes - Edital n. 06/2018. [2018]. Disponível em: https:// www.capes.gov.br/educacao-basica/programa-residencia-pedagogica. Acesso em: 3 jun. 2019.

CHAUÍ, Marilena. Convite à Filosofia. 4. ed. São Paulo: Ática, 1995. CORDI, Armando et al. Para Filosofar. São Paulo: Scipione, 1995. COTRIM, Gilberto. Fundamentos da Filosofia: história e grandes temas. São Paulo: Sarairva, 2008. 
FÁVERO, Altair Alberto, RAUBER, Jaime José \& KOHAN, Walter Omar(org). Um olhar sobre o ensino de filosofia. Ijuí: Editora Unijuí, 2002.

JAPIASSU, Hilton. O mito da neutralidade científica. Rio de Janeiro: Imago, 1981.

KANT, Immanuel, O que é Ilustração. In: WEFORT, F. (org.). Os clássicos da política. Saõ Paulo: Ática, 2011. v. 2. p. 83-85.

LORIERI, Marcos Antônio. Filosofia: fundamentos e métodos. São Paulo: Cortez, 2002.

MARCONDES, Danilo. Textos Básicos de Filosofia: dos pré-socráticos a Wittgenstein. Rio de Janeiro: Zahar, 1999.

MEC - MINISTÉRIO DA EDUCAÇÃO E CULTURA. Parâmetros Curriculares Nacionais Para o Ensino Médio. Brasília: MEC, 1998.

NETO, Henrique Nielsen. (org.). O Ensino da Filosofia no $2^{\circ}$ grau. São Paulo: Sofia Editora SEAF, 1986.

PIMENTA, Selma Garrido. O estágio na formação dos professores: unidade teoria e prática. São Paulo: Cortez, 1994. 
